\title{
A História de uma Pioneira da Psicanálise Brasileira: Um Estudo Historiográfico sobre Virgínia Bicudo
}

\author{
Iúri Yrving Müller da Silva² \\ Universidade Estadual Paulista, Assis-SP, Brasil
}

\begin{abstract}
Abrão, J. L. (2010). Virgínia Bicudo: A trajetória de uma psicanalista brasileira. São Paulo: Arte e Ciência.
\end{abstract}
O estilo fluido repleto de imagens e leveza denota a generosidade do autor de Virgínia Bicudo: A trajetória de uma psicanalista brasileira com os leitores. Sem retóricas acrobáticas e longe de reducionismos descritivos presentes em muitas biografias, oferece-nos um manuseio prático do livro, a fim de que possamos usá-lo de acordo com nossas expectativas, necessidades e desejos. Já no início, o leitor é recebido pela escrita lúcida de Maria Helena I. Teperman e de Antonio Luiz Serpa Pessanha (2010).

Reconhecendo o fruto de um trabalho intenso, a Psicanálise e os psicanalistas brasileiros contraem uma dívida de gratidão com o Professor Jorge Abrão. O mesmo amplia o universo de referências históricas sobre a implantação e difusão da Psicanálise em nosso país. Ao escrever sobre a psicanalista Virgínia Bicudo, revela a história viva de uma mulher pioneira na Psicanálise brasileira. Assim, reconhecendo na biografia contextualizada de vanguardistas da Psicanálise brasileira uma trajetória e sintetizando todo esse processo na busca de compreensão e apreensão de seu mundo, narram-se experiências nas quais práticas psicanalíticas possibilitaram a difusão e expansão de uma ciência. Desta maneira, procura-se reafirmar em biografias atuais, valendose da historiografia da Psicanálise, a participação plural do desenvolvimento individual e coletivo dos principais personagens da Psicanálise.

Por meio da metodologia historiográfica da Psicanálise, vislumbra-se uma maior capacidade, por parte do autor, de captar o espaço da subjetividade dos biografados, ampliando as fronteiras entre o pensar, o sentir e o agir dos mesmos. Por meio de fontes orais e documentos históricos são oferecidas possibilidades de ampliar, também, o nível de veracidade dos acontecimentos históricos coletivos, ou seja, o espaço em que as ações ocorreram. E é aí, nesse âmbito, que o biógrafo pode verdadeiramente reconstruir a história, pois, do contrário, valendo-se apenas de uma fonte para a coleta de dados, restringiria a análise desses dados a uma biografia calcada

\footnotetext{
${ }^{1}$ Endereço para correspondência:

Iúri Yrving Müller da Silva. Universidade Estadual Paulista. Seção de PósGraduação. Programa de Pós-Graduação em Psicologia. Avenida Dom Antonio, 2100. CEP 19.806-900. Assis-SP, Brasil.E-mail: iurimuller@, bol.com.br
}

em uma abordagem historiográfica descritiva, contrariando a tendência atual que privilegia a abordagem da historiografia contextual (Roudinesco, 2000).

É nessa perspectiva que a presente obra foi elaborada pelo autor, Psicólogo, Doutor em Psicologia Escolar e do Desenvolvimento Humano pelo Instituto de Psicologia da USP, Professor do Departamento de Psicologia Clínica da Faculdade de Ciências e Letras da Unesp, orientador do Programa de Pós-Graduação em Psicologia e Sociedade e Supervisor do Centro de Pesquisa Aplicada Dr ${ }^{\mathrm{a}}$ Betti Katzenstein. Jorge tem desenvolvido, nos últimos anos, pesquisas em psicanálise de crianças e adolescentes e história da psicanálise no Brasil. Entre suas pesquisas publicadas de cunho historiográfico, destaca-se o livro A história da psicanálise de crianças no Brasil, publicado em 2001, e o capítulo intitulado "Um inventário das relações entre educação e psicanálise no Brasil: perspectiva histórica", publicado em 2003 no livro Educação e Psicanálise: História, atualidade e perspectivas.

Em cada um dos dezoito capítulos, preciosidades históricas apresentam os dilemas e as angústias do viver de uma mulher durante o século XX. Contribui para essa ampliação a forma como o autor compõe seu discurso, privilegiando o impacto e a eficácia com que os acontecimentos narrados se deram. Ou seja, ciente de sua função de psicólogo e historiador, Abrão não se propõe a crítica literária, mas sim a aprofundar a História da Psicanálise no Brasil, estabelecendo conexões e evocando diversos conceitos da Psicanálise.

Para exemplificar, seguem resumos dos capítulos 2 e 3. O segundo capítulo - "O legado dos anos de formação escolar: entre a Escola e a Higiene Mental" - aponta como a formação na Escola Normal, o curso de Educadora Sanitária no Instituto de Higiene, o curso de Ciências Sociais na Escola Livre de Sociologia e Política de São Paulo influenciaram a posterior formação da Psicanalista Virgínia Bicudo. "O encontro com a Psicanálise" é o título do terceiro capítulo, constatando que o primeiro contato de Virgínia Bicudo com a psicanálise foi no ano de 1936, no primeiro ano do curso de Ciências, mais especificamente na disciplina de Psicologia Social e depois com Durval Marcondes, o principal difusor da Psicanálise em São Paulo. Os primeiros contatos de Virgínia Bicudo com Marcondes datam do período de 1936 a 1938. Época em que Marcondes realizara a proeza, após várias tentativas, de trazer para o Brasil a analista alemã de 
origem judia $\mathrm{Dr}^{\mathrm{a}}$ Koch e concretizar a possibilidade da formação de analistas em nosso país. Iniciou a análise com a mesma, em 1937, sendo a primeira mulher a deitar em um divã no hemisfério sul. $\mathrm{O}$ destaque conferido à biografada, neste capítulo, evidencia seu pioneirismo do movimento psicanalítico de São Paulo, tornando-se a primeira profissional não médica a interessar-se pela Psicanálise, com a peculiaridade de que este interesse de tomar a psicanálise unicamente como sistema teórico, entendendo-a também como técnica terapêutica, migrando, assim, de um interesse restrito ao estudo teórico do tema, em direção à formação psicanalítica e, consequentemente, à prática clínica. A construção dos capítulos posteriores segue direcionamento semelhante ao adotado nos capítulos anteriores e privilegia o viés histórico. Concluindo, no livro Virgínia Bicudo: A trajetória de uma psicanalista brasileira, o autor tem como proposta central narrar a singular carreira de uma psicanalista pioneira, que deixou atrás de si realizações desde o início do século XX. Desde o interesse precoce pela Psicanálise que desenvolvera no curso de Ciências Sociais da Escola Livre de Sociologia e Política de São Paulo, onde ingressou no ano de 1936, até o cargo de membro da diretoria da Sociedade de Psicanálise de São Paulo e coordenadora do Instituto desta instituição. Mesmo ocupando cargos estratégicos na Sociedade de Psicanálise de São Paulo, desde o início de sua primeira formação, foi a partir da década de 1960, ao retornar de Londres - onde esteve nos anos anteriores aprimorando seus conhecimentos, tendo contato direto com o grupo e as teorias de Melanie Klein -, que Virgínia Bicudo consolida sua liderança no grupo de São Saulo. Salientando e introduzindo fortemente a importância da Psicanálise de Crianças como instrumento didático na formação dos analistas brasileiros e na difusão, consolidação e reconhecimento desta prática em nosso país. Sempre confiante no poder de transformar realidades sociais por meio da Psicanálise, apostou desde o início de seu trabalho, primeiro como Professora primária educadora sanitária do Instituto de Higiene Mental de São Paulo, na possibilidade de favorecer a aprendizagem e o desenvolvimento de crianças e jovens em situação de fracasso escolar.

\section{Referências}

Roudinesco, E. (2000). Como escrever a história da psicanálise? Jornal de Psicanálise, 33(60/61), 139-146.

Abrão, J. L. F. (2001). A história da psicanálise de crianças no Brasil. São Paulo: Escuta.

Abrão, J. L. F. (2003). Um inventário das relações entre educação e psicanálise no Brasil: Perspectiva histórica. In M. L. Oliveira (Org.), Educação e psicanálise: História, atualidade e perspectivas (pp. 125-142). São Paulo: Casa do Psicólogo.
Iúri Yrving Müller da Silva é doutorando em Psicologia pelo Programa de Pós-graduação em Psicologia e Sociedade da Faculdade de Ciências e Letras da Universidade Estadual Paulista, campus Assis-SP.

Recebido: $15 / 02 / 2011$

$1^{a}$ revisão: 03/04/2011

Aceite final: 22/06/2011 